\title{
104. Some Observations on the Transplantation of Skin upon the Annular Tympanic Cartilage in Adult Frogs.
}

\author{
By Iwane SaTo. \\ Zoological Institute, Kyoto Imperial University. \\ (Comm. by C. IshiKaw A, M.I.A., June 12, 1934.)
}

In larval Amphibians the formation of the annular tympanic membrane is determined by the presence of an annular tympanic cartilage under the membrane. This conditional development of the latter is still possible in the skin of young frogs newly metamorphosed (O. M. Helff 1934). The question is now asked if it is possible to confirm any trace of this determining power of the annular tympanic cartilage in a fully grown frog. My experiments were planned to establish this point.

Material and Methods. The experiments were performed during the last autumn at the suggestion of Prof. Yô K. Okada with adult frogs, Rana nigromaculata, metamorphosed probably 2 or 3 years before. The animal was anaesthetized with ether, and the skin of the neck region, which contains the tympanic membrane, was removed from the underlying tissues. Care was particularly paid not to injure the lamina propria and cartilagious parts. A piece of skin of approximately the same form and size was next removed from the abdomen of another animal. This was transplanted by thread and needle into the wound area from which the tympanic membrane was removed. Reciprocally, the removed tympanic membrane was transplanted into the abdomen of another individual.

External Changes. In a few days the transplanted piece fused with the surrounding skin of the host and at the same time adhered to the annular tympanic cartilage on which it was grafted so that the circular outline of the latter could be seen externally. Then pigmentation occurred from the periphery toward the center. Sometimes hyperaemia took place at the point where the columella was attached. Thus, 6 weeks after the operation the central part of the transplanted skin above the annular tympanic cartilage became quite similar to a tympanic membrane at least in appearance, showing the dark brownish hue such as we see in the normal structure. The characteristic iridescence was, however, usually not attained. In general, degrees of macroscopic 
No. 6.] Some Observations on the Transplantation of Skin upon the Annular. 379

change were correlated with the time elasped, and the process carried out more slowly by far than in the case of newly metamorphosed frogs studied by O. M. Helff.

- Histological Observation. Also from the histological point of view, the newly formed tympanic membrane showed resemblance to the normal one. The stratum spongiosum was greatly reduced in thickness and chromatophores made their appearance. A still more noticeable change was the degeneration of mucous glands in the transplanted skin. They were observed as cellular masses in the stratum spongiosum, losing their contents. In some specimens the degeneration was very acute and the majority of glands were in atrophy, the place formerly occupied by them becoming vacant. But the transfomed tympanic membrane was the same thickness everywhere, whereas in the normal one the thickest part is the middle where the columella attaches and from this part thins out on either side.

Reciprocal Transplantation. A piece of skin which was removed from the tympanic area was transplanted into the abdomen. About 4 weeks later, the transplanted skin began to lose its pigment. The iridescence and dark brownish coloration peculiar to the tympanic membrane disappeared almost altogether. Although the original structure was thus obscured in the transplant, it was still possible to distinguish the outline of the original tympanic area from the surrounding abdominal skin even 8 weeks after the operation.

So far the main results of my experiment are that, even in the adult frog the abdominal skin can be transformed into the tympanic membrane when it is brought in contact with the annular tympanic cartilage. So it may be concluded that the annular tympanic cartilage gives necessary stimuli both for differentiation and maintenance of the structure of the tympanic membrane not only in developmental but also in adult condition.

In closing the description, I wish to express my hearty thanks to Prof. Okada for his kind direction.

\section{References.}

Helff, O. M. 1928. Studies on Amphibian Metamorphosis. 3. The influence of the annular tympanic cartilage on the formation of the tympanic membrane. Phsiol. Zooll. 1.

- O. M. 1931. Studies on Amphibian Metamorphosis. 7. The influence of the columella on the formation of the lamina propria of the tympanic membrane. Jour. Exper. Zoöl. 59.

- O. M. 1931. Studies on Amphibian metamorphosis. 13. The stability and growth of annuran tympanic membrane following larval involution. Biol. Bull. 66 . 